\title{
ASO Visual Abstract: Time to Surgery and Thyroid Cancer Survival in the United States
}

\author{
Scott C. Fligor, MD ${ }^{1,2}$, Betzamel Lopez, BS $^{2}$, Nishant Uppal, BS ${ }^{2,3}$, Carrie C. Lubitz, MD, MPH, FACS ${ }^{2,4}$, and \\ Benjamin C. James, MD, MS, FACS ${ }^{1,2}$ \\ ${ }^{1}$ Department of Surgery, Beth Israel Deaconess Medical Center, Boston, MA; ${ }^{2}$ Harvard Medical School, Boston, MA; \\ ${ }^{3}$ Harvard Business School, Boston, MA; ${ }^{4}$ Department of Surgery, Massachusetts General Hospital, Boston, MA
}

The first study to investigate time to surgery in papillary thyroid cancer using the National Cancer Database included 103,812 adults with papillary thyroid cancer from 2004 to 2016 (https://doi.org/10.1245/s10434-021-09797-z). The median follow-up period was 55.2 months (interquartile range, 28.4-89.5 months). Increasing time to surgery was associated with increased mortality. In the subgroup analysis, increasing delay was associated with worse overall survival for $\mathrm{T} 1, \mathrm{~T} 2$, and $\mathrm{T} 3$ tumors, but not $\mathrm{T} 4$ tumors. Further research is necessary to assess the impact of surgical delay on disease-specific survival.

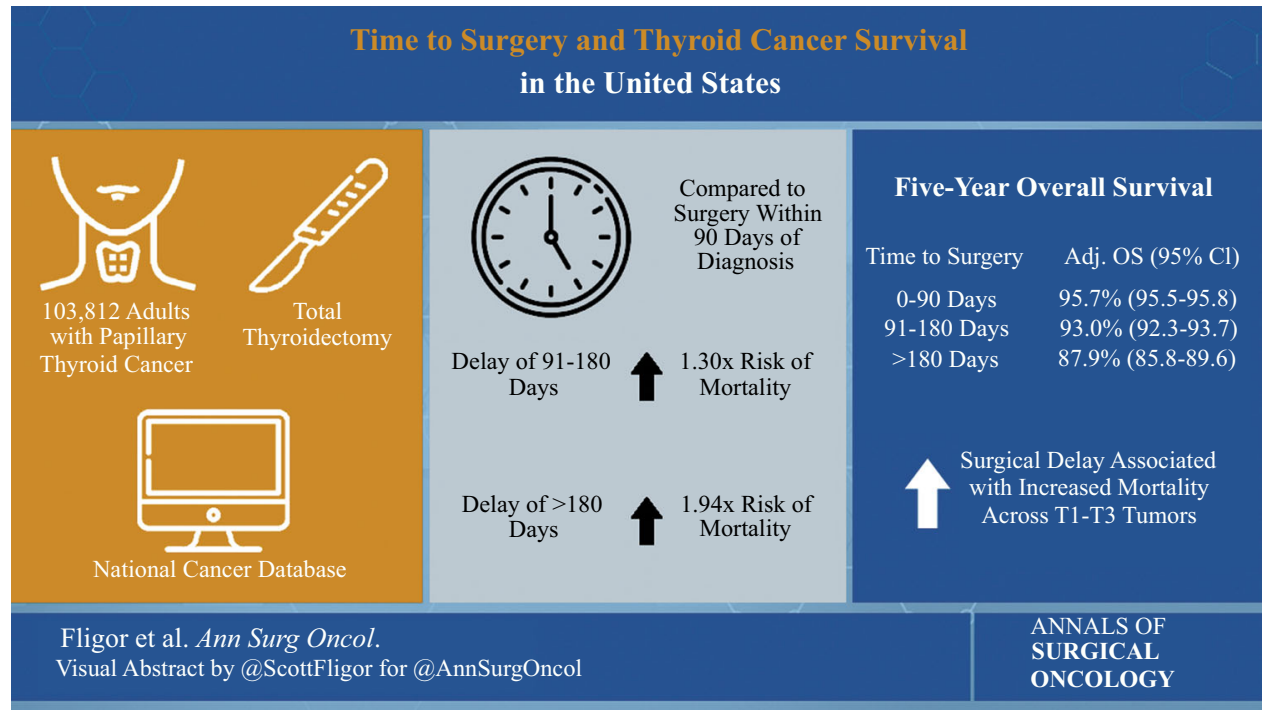

Dr. Scott C. Fligor and Ms. Betzamel Lopez should be considered cofirst authors.

(C) Society of Surgical Oncology 2021

B. C. James, MD, MS, FACS

e-mail: bjames1@bidmc.harvard.edu
ACKNOWLEDGMENT This work was conducted with support from National Institutes of Health Award UL1 TR002541. Dr. Lubitz also is supported by the National Institutes of Health/National Cancer Institute Award R37 CA23195.

DISCLOSURES There are no conflicts of interest.

Publisher's Note Springer Nature remains neutral with regard to jurisdictional claims in published maps and institutional affiliations. 